\title{
Backrest Shape Affects Head-Neck Alignment and Seated Pressure
}

\author{
Atsuki Ukita, MS ${ }^{1,2}$; Shigeo Nishimura, B.Eng. ${ }^{3}$; \\ Hirotoshi Kishigami, Ph.D. ${ }^{4}$ and Tatsuo Hatta, Ph.D. ${ }^{4 *}$ \\ ${ }^{1}$ Graduate School of Health Sciences, Hokkaido University, Sapporo, JAPAN. \\ ${ }^{2}$ Department of Occupational Therapy, Hokuto Hospital, Obihiro, JAPAN. \\ ${ }^{3}$ Division of Rehabilitation Engineering, Counseling Office, Hokkaido Government, \\ Sapporo, JAPAN. \\ ${ }^{4}$ Faculty of Health Sciences, Hokkaido University, Sapporo, JAPAN.
}

Submitted January 2015. Accepted for publication March 2015.

\begin{abstract}
Unstable back support against gravity results in a forward head posture and contributes to buttocks pressure ulcers. However, the association between these health problems and a wheelchair backrest is unclear. Our newly developed wheelchair (N-WC) supports the back of the pelvis and thorax from obliquely underneath. The purpose of this study was to investigate the effect of different backrest shapes on head-neck alignment and seated pressure. Data from 28 healthy subjects were analyzed. Outcome measures were head-neck alignment angles, support angles of the backrest, and pressure distributions on the supporting surfaces. Compared with a typical wheelchair that has a flat backrest, the seat pressure decreased and the center of pressure was located in the middle of both the seat and backrest in the N-WC. Moreover, the head-neck alignment when seated in the $\mathrm{N}-\mathrm{WC}$ was upright. These results highlight the importance of the shape of the wheelchair backrest.
\end{abstract}

Keywords: Wheelchair, backrest, sequence alignment, pressure, three-dimensional image

\section{INTRODUCTION}

Wheelchair is one of the most commonly used assistive devices for enhancing the personal mobility of people with disabilities. An estimated $1 \%$ of the world's population, or over 70 million people, require the use of a wheelchair [1,2]. Wheelchair is also one of the most important assistive devices for the elderly [3]. Aging in Japan is progressing at an unparalleled rate compared with other countries $[4,5]$. Approximately $25 \%$ of the total population is currently over the age of 65 , and this is projected to increase to $39.9 \%$ by 2060 [6]. In addition, the need for wheelchairs is highlighted by approximately $20 \%$ of health insurance covering the use of wheelchair service [7]. In a survey of elderly wheelchair users residing in care facilities, more than half of those surveyed were identified as having problems with wheelchair fit (e.g., poor posture and discomfort) [8].

*Corresponding author: Tatsuo HATTA, Ph.D, Professor, Faculty of Health Sciences, Hokkaido University, North 12, West 5, Kita-ku, Sapporo, Hokkaido, 060-0812, Japan, Phone/Fax: +81-11-706-3335, E-mail: thatta@hs.hokudai.ac.jp. Other authors: a-ukita@hs.hokudai.ac.jp; dragon522jp2001@ybb.ne.jp; kishi@ med.hokudai.ac.jp. 
A typical wheelchair (T-WC) has a linear backrest with a flat supporting surface. The basic structure of a T-WC makes it inexpensive and easy to use. However, T-WCs are not suitable for those who use a wheelchair as their primary form of mobility or have postural seating problems [9]. In particular, the elderly are unable to maintain a sitting position in this type of wheelchair [10].

The structural incompatibility between the natural thoracic curvature and the flat supporting surface of the T-WC backrest causes seating problems. This incompatibility contributes to poor pelvic support as a gap arises between the pelvis and the lower backrest. If the pelvis tilts due to instability, pressure concentrates in the sacrum or on one side of the ischium, and the risk of developing pressure ulcers or having an awkward posture increases, especially when sitting for long periods [11]. Concurrently, from a kinematic perspective, the mass of the head, neck, and trunk accounts for $64.4 \%$ of total body weight [12], and this mass is positioned forward relative to the spine when seated upright. Thus, a forward mass moment occurs when trying to keep the upper body upright under the influence of gravity. Maintaining mass balance in this posture would require continuous muscle power. Healthy people would have sufficient power to maintain this posture unconsciously; however, this may not be the case for elderly with decreased muscle or physical strength due to aging. In addition, the head position of elderly persons tends to be located more forward than in young people [13-16]. With the decrease in activity, it is not unusual to find elderly persons in this posture for a long time in a clinical setting. Thus, wheelchair-related assessments and interventions that significantly improve activities of daily living are considered important medical practices.

Previous studies suggested that the shape of the wheelchair backrest affects the seated posture and the sitting-related problems of the user [17-22]. For instance, increasing the backward inclination of the backrest above $120^{\circ}$ reduced buttock pressure. Most pressure ulcers are avoidable [23], and the shape of the backrest may have a role in maintaining low buttock pressure and good perfusion. A backrest with lumbar support promoted respiratory function, alleviated discomfort, and adjusted the position of the pelvis. In addition, a combination of multiple adjustments (e.g., curved backrest posts, backrest post rotation, and strap adjustment) was effective in supporting the back. Thus, the backrest is an important aspect of wheelchairs in relation to pelvis-trunk alignment and pressure ulcers. However, few studies have investigated the relationship between head-neck alignment and backrest shape.

We considered that the position of the head and neck is affected by whether or not the trunk and pelvis support corresponds with the spine structure. The current body of research clearly indicates that the visual, somatosensory, and proprioceptive systems of the cervical spine are paramount in controlling posture and balance against gravity [24-25]. Therefore, head-neck alignment is an important point of observation in wheelchair sitting posture.

To minimize the torque generated by the head-trunk mass, we used a newly developed wheelchair (N-WC) that was designed from the viewpoint of biomechanics. To support the trunk mass, the backrest posts of the N-WC were curved backwards and the tension adjustment belts were equipped with pelvic and thoracic parts. The purpose of this study is to investigate the effect of backrest shape on the head-neck alignment 
and seated pressure. We hypothesized that the position of the head is closer to the midline in the N-WC than in the T-WC. Furthermore, we hypothesized that the N-WC provides a more evenly distributed pressure in the back and a reduced maximum pressure on the buttocks.

\section{METHODS}

\subsection{Subjects}

Participants comprised 28 healthy volunteers (15 men, 13 women; age [mean \pm SD, range], $23.1 \pm 2.01,21-29$ years; weight, $60.7 \pm 10.55,40-88 \mathrm{~kg}$; height, $167.4 \pm 7.17$, $151-183 \mathrm{~cm})$. Exclusion criteria included presence and history of any diseases (e.g., cervical or lower back orthopedic diseases, neurologic disorders, heart failure) that affect sitting capacity and endurance. This study was approved by the Institutional Review Board of Hokkaido University Graduate School of Health Sciences (approval number: 11-26), Japan. All subjects provided written informed consent to participate.

\subsection{Wheelchairs}

We used two types of wheelchair in this study. Both wheelchairs had a sling sheet that stretched over the contact surface, with adjustable tension for postural support. Figure 1 shows the backrest post and tension adjustment structure for each wheelchair. The N-WC (NA501A, Nissine Medical Industries, Japan.) was adjusted based on measurements for the average Japanese adult male (weight $\sim 60 \mathrm{~kg}$; height $\sim 170 \mathrm{~cm}$ ) [26]. The N-WC had

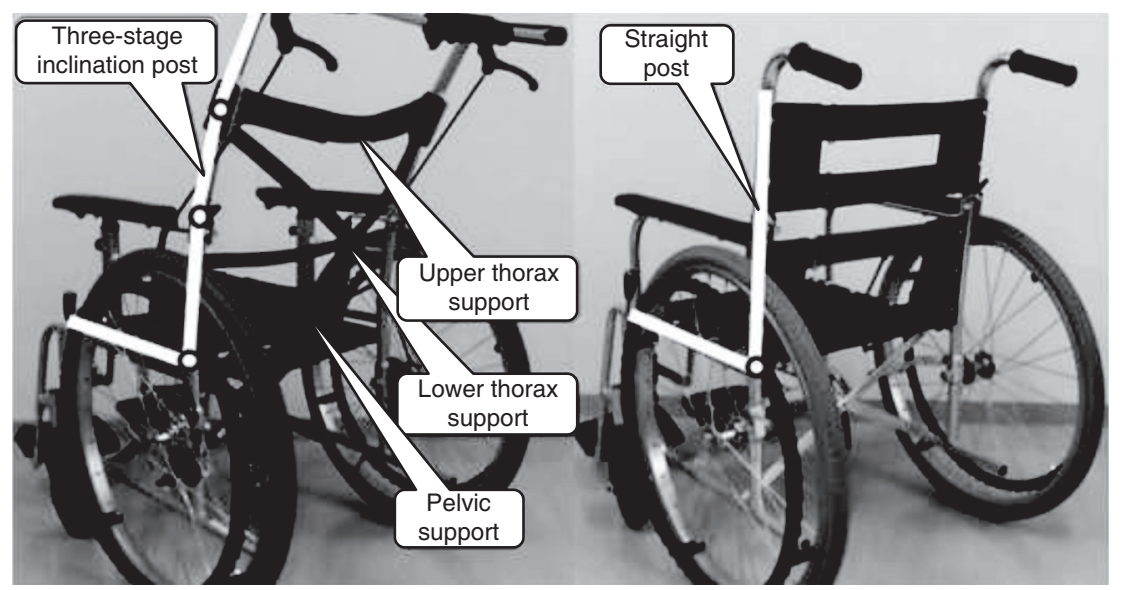

Figure 1. Different backrest structures of the two wheelchairs tested. Left: N-WC. Right: T-WC. The sling seat of the backrest was removed to standardize the experimental conditions. Both the seat and backrest dimensions were $400 \times 400 \mathrm{~mm}^{2}$. The seat backward inclination angles were $2.9^{\circ}$ for both wheelchairs. The seat-backrest angle (SBA) of the T-WC was $96^{\circ}$. The SBAs of the N-WC were $100^{\circ}$ for the pelvic support, $110^{\circ}$ for the lower thorax support, and $121^{\circ}$ for the upper thorax support. 


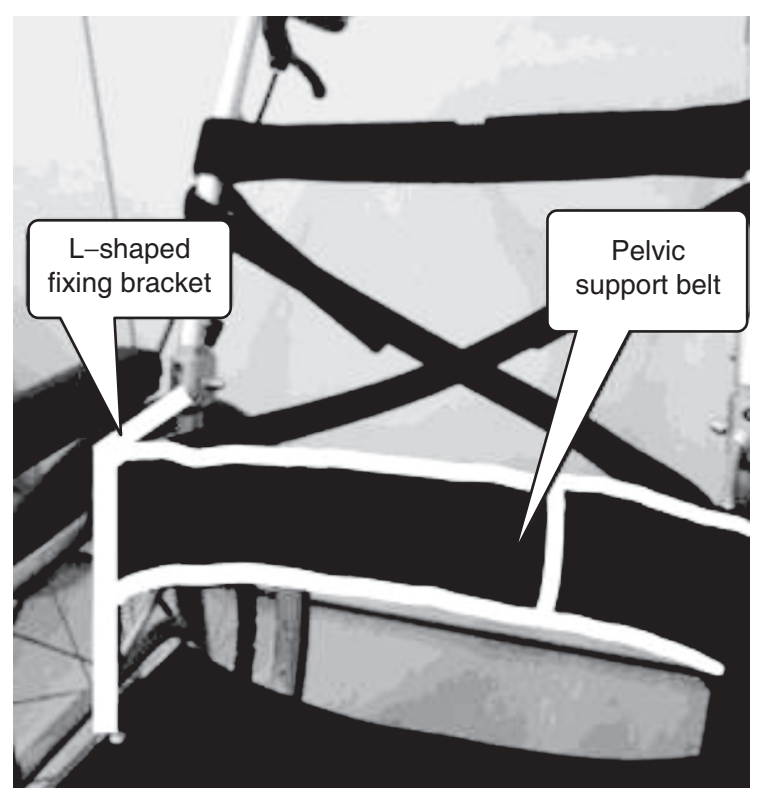

Figure 2. The structure of the pelvic support belt. The pelvic support belt can create different inclinations of the pelvis depending on the depth and angle of contact. When seated in the wheelchair, the back and side of the user's pelvis were surrounded by the belt.

three tension-adjustable Velcro belts, and the backrest posts were inclined backward in three stages. The three belts were the pelvis (PL), the lower thorax (LT), and the upper thorax (UT) support belts. The PL support belt, 100-mm wide, consisted of two Velcro belts, and hung between the L-shaped fixing brackets. The fixing brackets were welded to the backrest posts (Figure 2). The LT support belts were 25 -mm-wide cross belts that ran diagonally from the top of the PL support belt to the lower end of the UT support belt. These belts supported the LT in the area from the top of the PL support belt to the intersection of the LT support belts. The UT support belt was bound to the left and right backrest posts. This 50-mm-wide belt was adjusted to avoid pressing into the scapula and thorax. This belt supported users when sitting in a relaxed posture. A seat cushion with a rounded rear edge was used for this study. The round PL support belt was set along the posterior end of the cushion. The intersection of the LT support belt was set $25.4 \mathrm{~mm}$ behind the PL belt.

To ensure the same standards for each wheelchair, we used a wheelchair with tension-adjustable belts and linear backrest posts as the T-WC (NA406A, Nissine Medical Industries, Japan). The belts were stretched tightly to reproduce the flat support surface. The same seat cushion was used to standardize seat surface conditions in both wheelchairs. These adjustments were made before conducting the experiment, and individual settings during the experiment were not changed. The only difference between the two wheelchairs was the backrest structure. 


\subsection{Protocol and Positioning Procedure}

Before the tests, participants filled out a questionnaire on their demographic data. To assess body alignment, markers were attached to the subjects who wore black lab coats to eliminate any bias in marker positions from clothing. Subjects were seated in the wheelchair, their line of vision was fixed horizontally, and their hands were placed on their thighs with the palms facing up. The buttocks were placed as far back on the seat as possible, their thighs were parallel with the seat surface, and their knees were flexed at $90^{\circ}[18,21,27]$. Subjects were instructed to sit naturally and remain motionless during the test. The side guards and footrests were removed to standardize the experimental conditions. If the sole of the foot did not contact the ground, the height of the gap was compensated using boards.

\subsection{Measurement of Head and Neck Angles}

To measure head-neck alignment, we recorded wheelchair seated posture in the sagittal plane from the side. Video images were analyzed using Dartfish (Dartfish Ltd., Switzerland), 2D motion analysis software used in basic and clinical research for postural assessment [28, 29]. Retro-reflective markers $14 \mathrm{~mm}$ in diameter were placed on the outer canthus of the eye, the tragus of the ear, and the spinous process of the seventh cervical vertebra. The markers were attached on the left side of the subject's body using double-sided tape. Using the Dartfish analyzer function, the head and neck inclination angles based on the markings were calculated, which reflected the main outcome of the head alignment. The angles were set based on previous studies [27, 30]. Figure 3 shows the definitions of the head and neck angles.

A

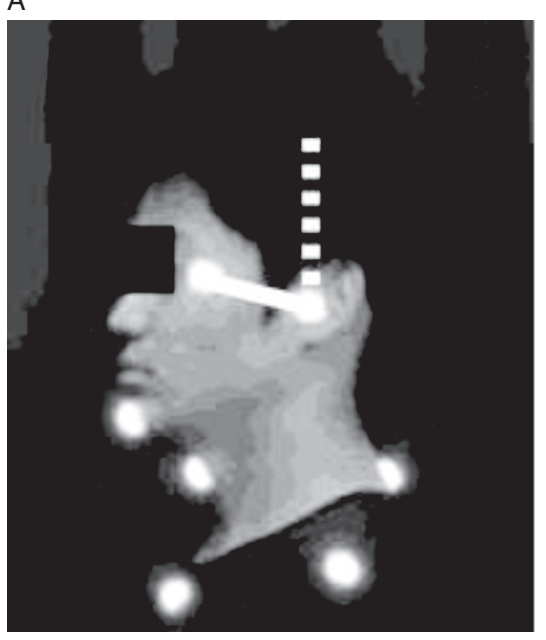

B

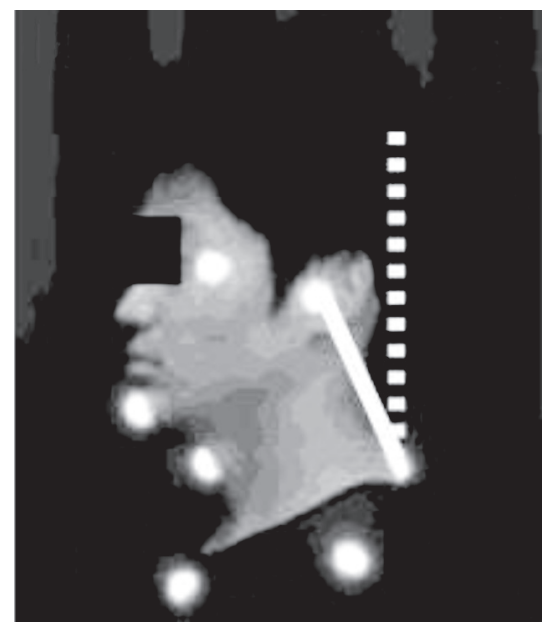

Figure 3. Definitions of head and neck angles. A: The head inclination angle is the angle formed between the outer canthus of the eye and the vertical line through the tragus of the ear. B: The neck inclination angle is the angle formed between the tragus and the vertical line through the seventh cervical vertebra. 


\subsection{Measurement of Supporting Surface Angle}

To visualize the shape of the backrest surface, and to calculate the support angle of each segment, first, the backrest shape was captured by the 3D motion analysis system, TRiDY (JFT-TEC, Japan). TRiDY is a non-contact 3D measurement system that uses multi-pattern projection with a data projector and has been used for wheelchair assessment [31]. It has a measurement field of $520 \times 690 \mathrm{~mm}^{2}$, which is wide enough for the wheelchair seating support surface, and a resolution of $1.1 \mathrm{~mm}$. The backrest shape was scanned from behind the wheelchair while each subject was seated. Scanned image data were saved on a personal computer and merged into a single 3D backrest image using RapidForm 2006 (3D Systems Inc., Japan), which supports solid modeling and is capable of rendering 3D shapes [32].

The angle based on the solid model was measured using AutoCAD 2012 (Autodesk Inc., USA). The horizontal and a perpendicular line were assumed based on the inclination of a backrest post in three dimensions along the back support surface. Straight-line approximation was conducted on the line using AutoCAD. Measurements of the back supported angles on the sagittal plane provided the pelvis angle (PLA), the lower thoracic angle (LTA), and the upper thoracic angle (UTA).

\subsection{Pressure Distribution}

Two Force Sensing Arrays (FSAs, Vista Medical Ltd., Canada) were used to collect pressure data at the seat and the backrest interfaces. The FSA is a $430 \times 430 \mathrm{~mm}^{2}$ flexible pressure mat with 256 sensors, and covers the total contact area between the subject and the wheelchair. The cell dimension is $26.9 \mathrm{~mm}$. The measured pressure range was $0-200 \mathrm{mmHg}$, and the accuracy of the pressure measurement was $\pm 10 \%$ of the full scale. To ensure reliability, the FSA was calibrated prior to the experiment [33]. The FSA was well rated in clinical measurements [34-35]. After the sitting posture stabilized, pressure was measured for approximately $30 \mathrm{~s}$. The maximum pressure, mean pressure, center of pressure, and sensing area were automatically calculated. From these values, the total pressures on both the back and seat were calculated.

\subsection{Statistical Analysis}

Data were analyzed using the Wilcoxon signed-rank test, based on non-normality. Statistical tests were conducted using PASW (SPSS Inc., USA) for Windows, with a significance level of 0.05 .

\section{RESULTS}

\subsection{Comparison of Head-Neck Alignment}

Figure 4 shows an example of the angle measurement. The results of head and neck angle measurements are shown in Table 1. There was no significant difference in the head inclination angle between the T-WC and the N-WC. The neck inclination angle of subjects in the $\mathrm{N}-\mathrm{WC}$ was smaller than that in the T-WC $(\mathrm{p}<0.05 ; \mathrm{Z}=-2.03)$. In other words, sitting in the N-WC, the subjects' heads were more upright in comparison with sitting in the T-WC. 


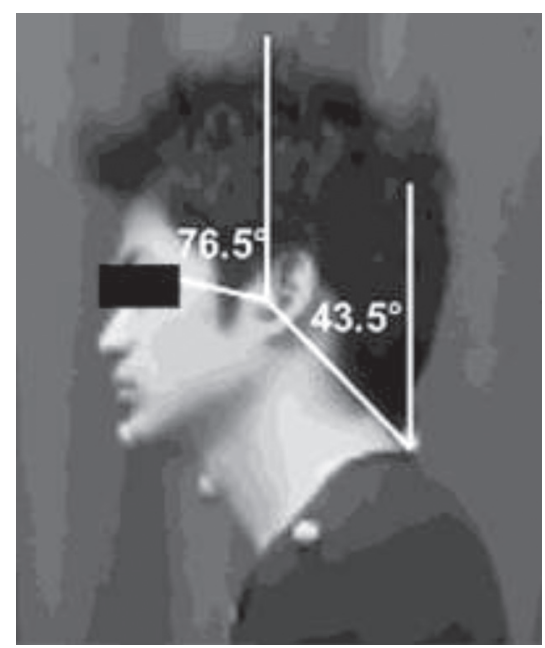

Figure 4. Example of angle measurement. The head and neck inclination angles were determined by the markers. The angles were displayed in real time on the analysis screen.

\subsection{Difference in the Supporting Surface and Support Angle}

The 3D images of the backrest support surface are shown in Figure 5. The T-WC backrest was flat and uniform, while that of the N-WC was multifarious and stereoscopic. Each backward inclination support angle was significantly larger in the N-WC than in the T-WC (Table 1). The maximum support angle was the LTA for both wheelchairs.

\subsection{Change in Seat and Back Pressures}

Figure 6 shows the pressure distribution for one exemplar case. In the T-WC, back pressure was concentrated in the upper area of the backrest plane, without a wide contact area to disperse the pressure (Figure 6B). In the seat plane, the highest pressure was observed around the ischial tuberosity, and the area of contact with the coccyx could be confirmed. Further, the load was biased to either ischial tuberosity (Figure 6D).

In the N-WC, pressure distributed from the middle to the lower backrest plane, with a wide contact area to disperse the pressure compared with T-WC (Figure 6A). In the seat plane, the highest pressure was also observed around the ischial tuberosity. However, the load on the ischial tuberosity was more uniform and no area of contact with the coccyx was observed (Figure 6C).

The measurement results are shown in Table 1. In the N-WC, the maximum and average seat pressures are lower by a factor of $\sim 0.7(\mathrm{p}<0.01 ; \mathrm{Z}=-2.98$ and -4.14$)$ compared with the T-WC, and the maximum and average back pressures approximately doubled $(\mathrm{p}<0.01 ; \mathrm{Z}=-3.12$ and -3.41$)$. The pressure sensing area on the seat 
Table 1. Pressure and angle data

\begin{tabular}{|c|c|c|c|c|c|c|c|}
\hline & & & & & & & \\
\hline & Meas & d variable & Mean & SD & Mean & SD & p-value \\
\hline Maximun & pressure & Seat plane & 68.3 & 46.72 & 49.2 & 29.00 & $<0.01$ \\
\hline$(\mathrm{mmHg})$ & & Backrest plane & 11.7 & 9.89 & 22.6 & 11.74 & $<0.01$ \\
\hline Average $\mathrm{p}$ & essure & Seat plane & 12.2 & 4.67 & 10.3 & 3.59 & $<0.01$ \\
\hline$(\mathrm{mmHg})$ & & Backrest plane & 4.2 & 2.68 & 5.8 & 3.11 & 0.06 \\
\hline Sensing a & $\mathrm{ea}\left(\mathrm{cm}^{2}\right)$ & Seat plane & 548.7 & 154.22 & 469.1 & 110.54 & $<0.01$ \\
\hline & & Backrest plane & 75.1 & 51.14 & 147.7 & 75.61 & $<0.01$ \\
\hline Total pres & & Seat plane & 107.7 & 38.89 & 79.1 & 28.50 & $<0.01$ \\
\hline$(\mathrm{mmHg} * \mathrm{c}$ & $\left.\mathrm{n}^{2} / \mathrm{kg}\right)$ & Backrest plane & 6.3 & 7.00 & 14.4 & 8.91 & $<0.01$ \\
\hline & & Horizontal center of seat & 18.3 & 1.83 & 20.5 & 1.46 & $<0.01$ \\
\hline Position ( & & Vertical center of seat & 13.1 & 3.08 & 19.6 & 2.02 & $<0.01$ \\
\hline & & Horizontal center of back & 18.9 & 6.13 & 19.4 & 3.99 & 0.43 \\
\hline & & Vertical center of back & 7.1 & 6.47 & 13.9 & 6.77 & $<0.01$ \\
\hline & Based on & Head inclination & 68.2 & 6.60 & 69.1 & 5.90 & 0.34 \\
\hline Angle & Dartfish & Neck inclination & 37.8 & 5.21 & 36.2 & 5.48 & $<0.05$ \\
\hline (degrees) & Based on & Upper thoracic & 102.3 & 2.55 & 111.6 & 4.27 & $<0.01$ \\
\hline & TRiDY & Lower thoracic & 107.7 & 3.00 & 119.7 & 4.05 & $<0.01$ \\
\hline & & Pelvis & 94.3 & 2.10 & 110.5 & 4.28 & $<0.01$ \\
\hline
\end{tabular}

Note: Data are presented as mean \pm standard deviation (SD).

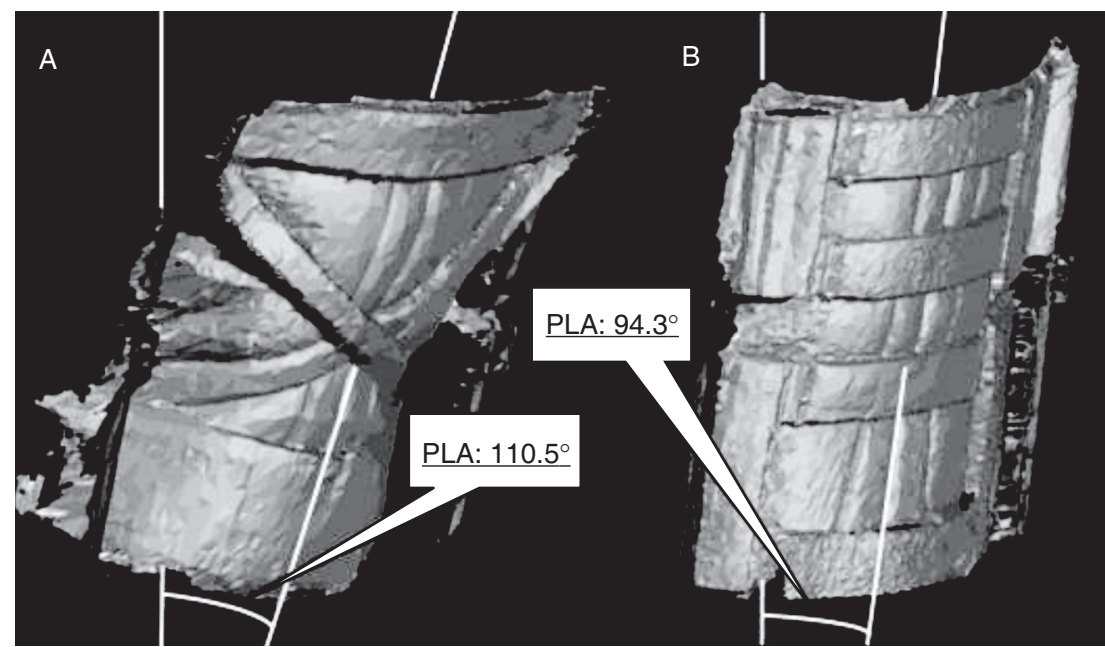

Figure 5. 3D backrest image and example of support angles. A: shape of the N-WC backrest. B: shape of the T-WC backrest. Backrest shapes were viewed obliquely from the back. As an example, the average values of the pelvic angle (PLA) are presented. 

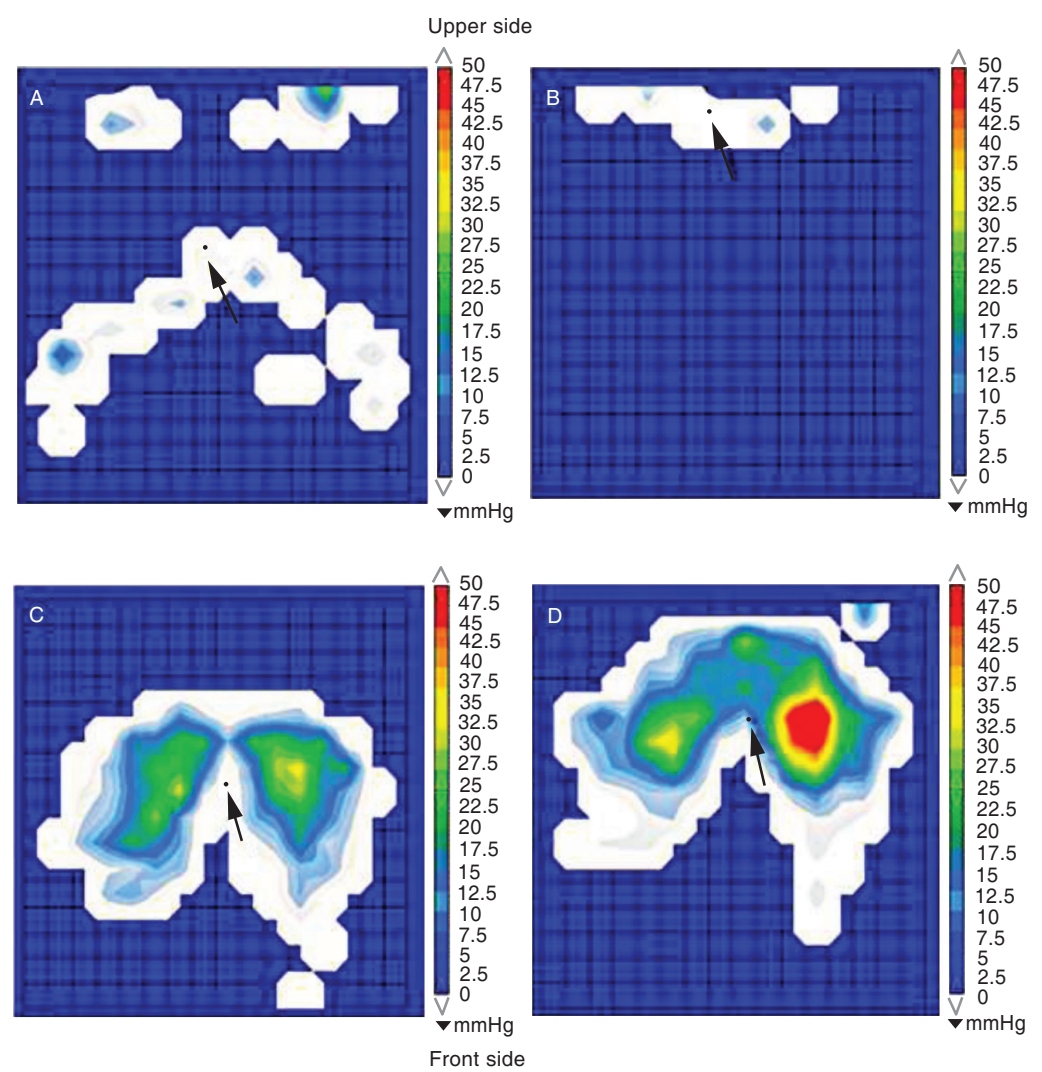

Figure 6. Typical example of the pressure distribution. A: the backrest plane of the N-WC. B: the backrest plane of the T-WC. C: the seat plane of the N-WC. D: the seat plane of the T-WC. Arrowhead: the center of pressure of each plane.

decreased by a factor of $\sim 0.8(\mathrm{p}<0.01 ; \mathrm{Z}=-3.84)$, and increased almost two-fold on the back $(\mathrm{p}<0.01 ; \mathrm{Z}=-3.98)$. The center of pressure of the $\mathrm{N}-\mathrm{WC}$ was more centralized than that of the T-WC for both support surfaces. The seat-to-back ratio in terms of the total pressure was $17: 1$ for the T-WC and $5: 1$ for the N-WC.

\section{DISCUSSION}

An elderly person may spend a long time sitting in a wheelchair [36], and therapists sometimes give priority to a seated posture for positioning rather than propelling $[8$, 37]. In other words, a wheelchair is an assistive device in which both mobility and postural stability are regarded as important. To facilitate both mobility and stability, each body mass should be in balance without resisting gravity; i.e., a forward or backward mass moment is minimized when maintaining a sitting posture. Additionally, 
the origin (or insertion) of muscles must be stable for active movement. To satisfy these conditions, we focused on the shape of the wheelchair backrest, which is directly in contact with the body.

In a static sitting posture, the shape of the backrest in the T-WC was a flat surface, as seen in Figure 5. The most backward convex part was a part of the upper-middle area of the backrest. Video images showed that this part would contact the thoracic kyphosis. Pressure was concentrated in the upper part of the backrest and not in the middle-lower part of the backrest. In addition, the PLA was smaller than the SBA, while other support angles were larger than the SBA. No changes were observed in the supporting surface of the lower part of the backrest when in contact with the body. This indicates that the pelvic part was not supported because the thorax only contacted the upper part of the backrest and a gap was evident between the pelvis and backrest.

For the N-WC, the shape of the backrest better conforms to the spinal cord than TWC (see Figure 5). The most backward convex part was the middle area of the backrest, i.e., the part in contact with the thoracic kyphosis. Pressure is distributed on not only the upper backrest but also the middle-lower area. In addition, all of the support angles were larger than SBA. These results indicate that the shape of the N-WC provided support along the kyphosis and there was no gap between the body and the supporting surface. Moreover, the optimal conditions for disc pressure and muscular activity were achieved when the backrest was inclined at $110^{\circ}$ to $120^{\circ}$ from the horizontal [38]. Support angles of the N-WC within this range should reduce physical discomfort.

The head-neck alignment was affected by the backrest shape. The neck inclination angle in the T-WC was greater than that in the N-WC; the neck was positioned forward in the T-WC. Because the support surface was flat, the shape of the backrest did not conform to that of the thoracic kyphosis and a local pressure distribution in the upper area of the backrest was noted in the T-WC.

This concentrated pressure heightened the reaction force as a forward torque from the backrest [39], and causing users to assume a bending posture. With poor support of the pelvis, the trunk bent under its own weight in the direction of gravity and the head was simultaneously displaced to the front. The burden on the musculoskeletal system decreased as the head and neck approached the neutral position [40]. The forward head posture observed in the T-WC should be avoided. By contrast, the backrest shape of the N-WC supported the middle and lower backs from obliquely backward, without a gap. Like the T-WC, a reaction force was generated at the center of pressure of the middle part of the backrest, but the trunk did not push forward because the direction of the reaction force was obliquely upward. Moreover, the trunk and pelvis were supported in the moderate backward inclination position in each segment, thus preventing the bending posture under the wheelchair user's own weight in the direction of gravity. Due to these kinematic effects, the head and neck remain upright and the burden on the musculoskeletal system is small in the N-WC. Although the change of the neck inclination angle was very small, the angle associated with the neck increases with age [14-15]. Even healthy subjects changed their alignment, and the impact on elderly or disabled individuals with swallowing or breathing problems could be substantial. 
The backrest shape also affected seated pressure. The seated pressure of the T-WC was high because the weight of the head and trunk was mostly loaded on the buttocks instead of being dispersed by the backrest. However, spreading the weight of the upper body over the backrest in the N-WC decompressed the ischial area; supporting the trunk and pelvis from the side creates these differences. Although a clear pressure value for preventing ulcers has not yet been established, generally speaking, continuous high pressure is associated with the risk of developing pressure ulcers [41-43]. Aging is also a risk factor for pressure ulcers [44]. Elderly individuals tend to sit for longer periods than younger people and often complain of buttock pain. Although cushions are normally used to prevent ulcers, the results presented here suggest that backrest shape of wheelchair is also an important factor. Wheelchairs should be designed taking ergonomic design parameters into consideration.

The generalizability of these results may be limited because only able-bodied persons participated in the present study, as a study involving wheelchair-confined individuals are difficult to conduct and receive IRB approval. Differences in backrest shape were confirmed to affect posture, and areas with gaps between the backrests and the body, indicating no support, are likely to be greater for the elderly and people with disabilities. However, the measured data cannot be applied directly to the elderly and people with disabilities. Although we believe that the stable static positioning for users who have poor functional capacity (e.g., older and/or disabled individuals who require assistance for activities of daily living, ADL) contributes to their daily activities, the current static study results do not apply to assess voluntary activities conducted while sitting in a wheelchair. It is necessary to investigate the effects of pelvis and thoracic support on functional activities based on the results of the current static study. Moreover, the pressure and postural change were not evaluated from the perspective of pressure ulcer etiology (i.e., shear force, friction force, moisture, and so on) [45] over the long term. Future studies including the measure of the shear or friction force should be conducted over longer periods, and include elderly subjects with poor muscular strength or hemiplegia patients with different physical conditions. Finally, there was no need to adjust the tension of the belts for each individual in this study because the impact of spinal deformities on healthy subjects is negligible. Therefore, we did not examine how adjusting the belts' tension affected the current results (e.g., magnitude of the contact pressure). This is to be investigated in future research.

\section{CONCLUSION}

Backrest shape affects head-neck alignment and seated pressure. Compared with conventional wheelchairs, the backrest of our newly designed wheelchair provides obliquely downward support to the pelvis and thorax, effectively promotes upright alignment of the head and neck, and reduces seated pressure. It is important for wheelchair users to be able to maintain a seated posture with their head and neck upright, while decreasing their buttock pressure and supporting each part of their back. Although this study was conducted with healthy individuals, it provided important knowledge for solving health problems such as forward head posture, head-neck pain, and buttocks pressure ulcers in wheelchair users. We believe that these findings are 
important to improving wheelchair user's health and contribute to helping users, clinicians, and manufacturers choose the most appropriate wheelchair seating systems. The current results suggest that when prescribing wheelchairs, attention should be paid to backrest shape in addition to the seat surface.

\section{CONFLICT OF INTEREST}

No commercial party having a direct financial interest in the results of the research supporting this article has conferred or will confer a benefit on the authors or on any organization with which the authors are associated.

\section{REFERENCES}

[1] World Health Organization. Guidelines on the provision of manual wheelchairs in less-resourced settings. Geneva, 2008. http:// www.who.int/ disabilities/ publications/ technology/ wheelchairguide lines/en/. Accessed January 10, 2015.

[2] World Health Organization. Wheelchair Service Training Package - Basic level. Geneva, 2012. http://www.who.int/disabilities/technology/wheelchairpackage/en/. Accessed January 10, 2015.

[3] Mortenson WB, Oliffe JL, Miller WC, Backman CL. Grey spaces: the wheeled fields of residential care. Sociology of Health \& Illness. 2012, 34(3):315-329.

[4] United Nations Department of Economic and Social Affairs. World Population Prospects: The 2012 Revision, Methodology of the United Nations Population Estimates and Projections, New York, 2014.

[5] Japan Ministry of Internal Affairs and Communication. Historical Statistics of Japan. Chapter 2 Population and Households. 2012. http://www.stat.go.jp/english/data/chouki/02.htm. Accessed January 14, 2015.

[6] Cabinet Office, Government of Japan. White paper on aging society. The aging situation and the implementation status of aged society measures, 2014. http:// www8.cao.go.jp/kourei/whitepaper/ w-2014/gaiyou/pdf/1s1s.pdf. Accessed January 14, 2015.

[7] Japan Ministry of Health, Labour and Welfare. Survey on care payment costs, 2014. (in Japanese) http://www.mhlw.go.jp/toukei/saikin/hw/kaigo/kyufu/13/dl/04.pdf. Accessed January 14, 2015.

[8] Giesbrecht EM, Mortenson WB, Miller WC. Prevalence and facility level correlates of need for wheelchair seating assessment among long-term care residents. Gerontology. 2012, 58(4):378-384.

[9] Green G, Young J. The provision of wheelchairs for older people in the United Kingdom. European Geriatric Medicine. 2011, 2(1):52-55.

[10] Rader J, Jones D, Miller LL. Individualized wheelchair seating: reducing restraints and improving comfort and function. Topics in Geriatric Rehabilitation. 1999, 15(2):34-47.

[11] Kemmoku T, Furumachi K, Shimamura T. Force on the sacrococcygeal and ischial areas during posterior pelvic tilt in seated posture. Prosthetics and Orthotics International. 2013, 37(4):282-288.

[12] Greene DP, Roberts SL. Body segment parameters, in: Kathy Falk (ed). Kinesiology: Movement in the Context of Activity. 2nd ed., Elsevier Mosby, USA, 2005, 168.

[13] Kuo YL, Tully EA, Galea MP. Video analysis of sagittal spinal posture in healthy young and older adults. Journal of Manipulative and Physiological Therapeutics. 2009, 32(3):210-215.

[14] Yukawa Y, Kato F, Suda K, Yamagata M, Ueta T. Age-related changes in osseous anatomy, alignment, and range of motion of the cervical spine. Part I: Radiographic data from over 1,200 asymptomatic subjects. European Spine Journal. 2012, 21(8):1492-1498.

[15] Park MS, Moon SH, Lee HM, Kim SW, Kim TH, Lee SY, Riew KD. The effect of age on cervical sagittal alignment: normative data on 100 asymptomatic subjects. Spine. 2013, 38(8):E458-463.

[16] Quek J, Pua YH, Clark RA, Bryant AL. Effects of thoracic kyphosis and forward head posture on cervical range of motion in older adults. Manual Therapy. 2013, 18(1):65-71.

[17] Park UJ, Jang SH. The influence of backrest inclination on buttock pressure. Annals of Rehabilitation Medicine. 2011, 35(6):897-906. 
[18] Lin F, Parthasarathy S, Taylor SJ, Pucci D, Hendrix RW, Makhsous M. Effect of different sitting postures on lung capacity, expiratory flow, and lumbar lordosis. Archives of Physical Medicine and Rehabilitation. 2006, 87(4):504-509.

[19] Grondin DE, Triano JJ, Tran S, Soave D. The effect of a lumbar support pillow on lumbar posture and comfort during a prolonged seated task. Chiropractic \& Manual Therapies. 2013, 21(1):21.

[20] Samuelsson K, Bjork M, Hansson AK, Rustner B. The effect of shaped wheelchair cushion and lumbar supports on under-seat pressure, comfort, and pelvic rotation. Disability and Rehabilitation: Assistive Technology. 2009, 4(5):329-336.

[21] Parent F, Dansereua J, Lacoste M, Aissaoui R. Evaluation of the new flexible contour backrest for wheelchairs. Journal of Rehabilitation Research and Development. 2000, 37(3):325-333.

[22] Jan YK, Crane BA, Liao F, Woods JA, Ennis WJ. Comparison of muscle and skin perfusion over the ischial tuberosities in response to wheelchair tilt-in-space and recline angles in people with spinal cord injury. Archives of Physical Medicine and Rehabilitation. 2013, 94(10):1990-1996.

[23] Black JM, Edsberg LE, Baharestani MM, Langemo D, Goldberg M, McNichol L, Cuddigan J; National Pressure Ulcer Advisory Panel. Pressure ulcers: avoidable or unavoidable? Results of the National Pressure Ulcer Advisory Panel Consensus Conference. Ostomy Wound Management. 2011, 57(2):24-37.

[24] Morningstar MW, Pettibon BR, Schlappi H, Schlappi M, Ireland TV. Reflex control of the spine and posture: a review of the literature from a chiropractic perspective. Chiropractic \& Osteopathy. 2005, 13:16.

[25] Treleaven J. Sensorimotor disturbances in neck disorders affecting postural stability, head and eye movement control. Manual Therapy. 2008, 13(1):2-11.

[26] Japan Ministry of Internal Affairs and Communication. Historical Statistics of Japan. Chapter 24 Health and Medical Care. 2012. http://www.stat.go.jp/english/data/chouki/24.htm. Accessed February $15,2015$.

[27] Straker LM, O’Sullivan PB, Smith AJ, Perry MC, Coleman J. Sitting spinal posture in adolescents differs between genders, but is not clearly related to neck/shoulder pain: an observational study. The Australian Journal of Physiotherapy. 2008, 54(2):127-133.

[28] Constand MK, Macdermid JC. Effects of neck pain on reaching overhead and reading: a case-control study of long and short neck flexion. BMC Sports Science, Medicine and Rehabilitation. 2013, 5(1):21.

[29] Borel S, Schneider P, Newman CJ. Video analysis software increases the interrater reliability of video gait assessments in children with cerebral palsy. Gait \& Posture. 2011, 33(4):727-729.

[30] van Niekerk SM, Louw Q, Vaughan C, Grimmer-Somers K, Schreve K. Photographic measurement of upper-body sitting posture of high school students: a reliability and validity study. $B M C$ Musculoskeletal Disorders. 2008, 9:113.

[31] Hatta T, Nishimura S, Inoue K, Yamanaka M, Maki M, Kobayashi N, Kishigami H, Sato M. Evaluating the relationships between the postural adaptation of patients with profound cerebral palsy and the configuration of the Seating Buggy's seating support surface. Journal of Physiological Anthropology. 2007, 26(2):217-224.

[32] Chang KH, Chen C. 3D shape engineering and design parameterization. Computer-Aided Design \& Applications. 2011, 8(5):681-692.

[33] Dey ZR, Nair NR, Shapcott N. Evaluation of the Force Sensing Application pressure mapping system. Journal of Medical Engineering \& Technology. 2013, 37(3):213-219.

[34] Miller SK, Aberegg L, Blasiole K, Parker M, Fulton J. A prospective assessment of sacral pressures in healthy volunteers seated upright and reclined with legs elevated in a recliner. Ostomy Wound Management. 2014, 60(9):52-59.

[35] Kim WJ, Chang M. A Comparison of the average sitting pressures and symmetry indexes between airadjustable and foam cushions. Journal of Physical Therapy Science. 2013, 25(9):1185-1187.

[36] Rader J, Jones D, Miller L. The importance of individualized wheelchair seating for frail older adults. Journal of Gerontological Nursing. 2000, 26(11):24-32. 
[37] Fuchs RH, Gromak PA. Wheelchair use by residents of nursing homes: effectiveness in meeting positioning and mobility needs. Assistive Technology. The Official Journal of RESNA. 2003, 15(2):151-163.

[38] Kroemer KHE, Grandjean E. Fitting the task to the human: A textbook of occupational ergonomics, 5th ed., Taylor \& Francis, UK \& USA, 1997, 75-78.

[39] Kobara K, Eguchi A, Watanabe S, Shinkoda K. The influence of the distance between the backrest of a chair and the position of the pelvis on the maximum pressure on the ischium and estimate shear force. Disability and Rehabilitation: Assistive Technology. 2008, 3(5):285-291.

[40] Greene DP, Roberts SL. Forces acting on the head and torso, in: Kathy Falk (ed). Kinesiology: Movement in the Context of Activity. 2nd ed., Elsevier Mosby, USA, 2005, 82-85.

[41] Reddy M, Gill SS, Kalkar SR, Wu W, Anderson PJ, Rochon PA. Treatment of pressure ulcers: a systematic review. JAMA. 2008, 300(22):2647-2662.

[42] Sprigle S, Sonenblum S. Assessing evidence supporting redistribution of pressure for pressure ulcer prevention: a review. Journal of Rehabilitation Research and Development. 2011, 48(3):203-213.

[43] Taule T, Bergfjord K, Holsvik EE, Lunde T, Stokke BH, Storlid H, Sørheim MV, Rekand T. Factors influencing optimal seating pressure after spinal cord injury. Spinal Cord. 2013, 51(4):273-277.

[44] Stojadinovic O, Minkiewicz J, Sawaya A, Bourne JW, Torzilli P, de Rivero Vaccari JP, Dietrich WD, Keane RW, Tomic-Canic M. Deep tissue injury in development of pressure ulcers: a decrease of inflammasome activation and changes in human skin morphology in response to aging and mechanical load. PLoS One. 2013, 14;8(8):e69223.

[45] National Pressure Ulcer Advisory Panel, European Pressure Ulcer Advisory Panel, Pan Pacific Pressure Injury Alliance. in: Emily Haesler (ed). Prevention and Treatment of Pressure Ulcers: Quick Reference Guide. Cambridge Media, Western Australia, 2014, 14-32. 


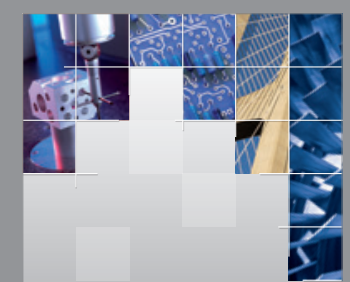

\section{Enfincering}
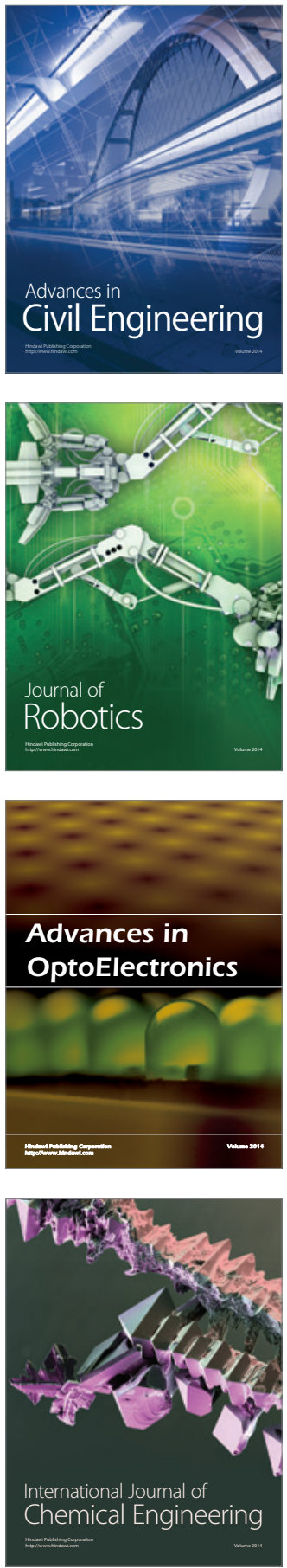

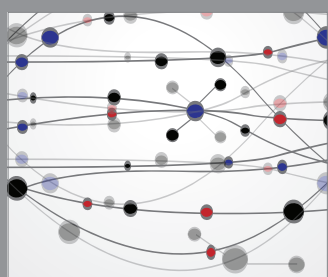

The Scientific World Journal

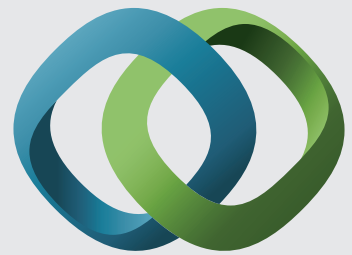

\section{Hindawi}

Submit your manuscripts at

http://www.hindawi.com
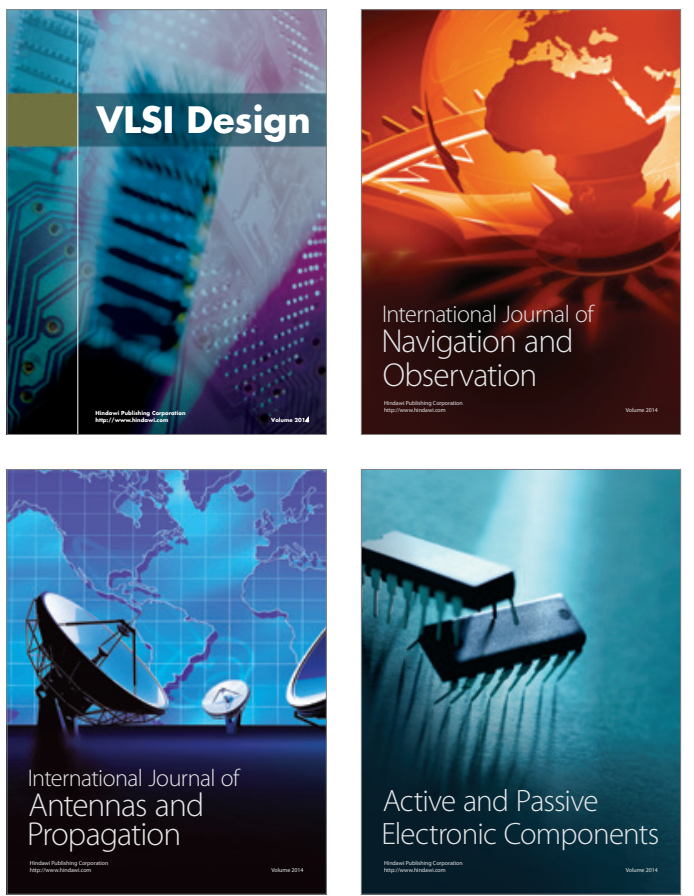
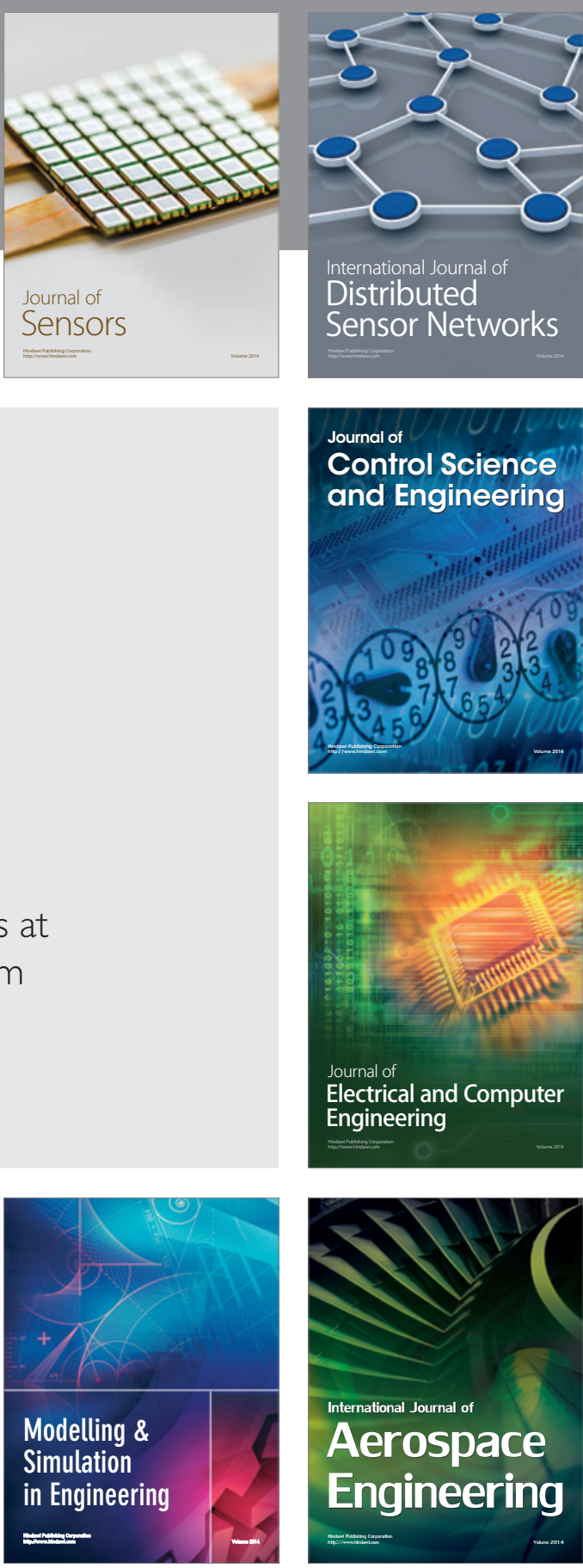

International Journal of

Distributed

Sensor Networks

Journal of

Control Science

and Engineering
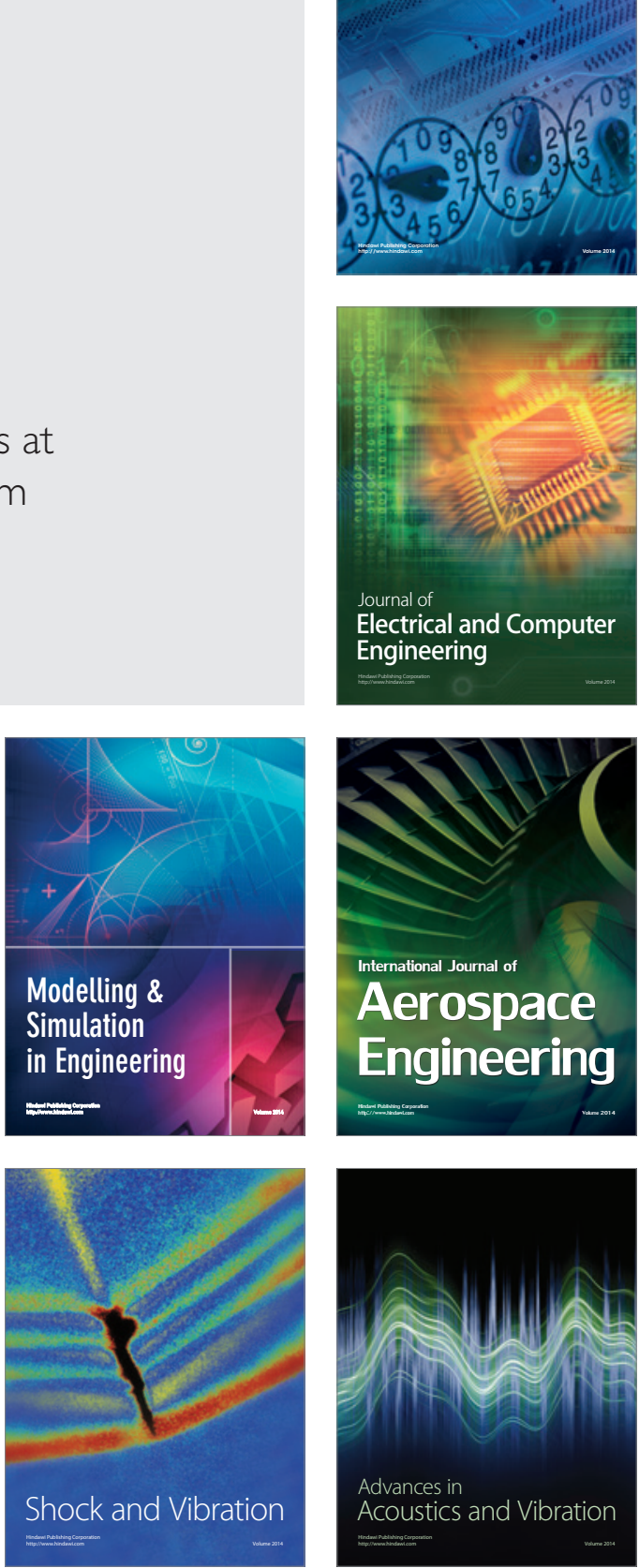